\title{
Effect of the duty cycle on the spark-plug plasma synthetic jet actuator
}

\author{
Mehmet Seyhan ${ }^{1, a}$, Yahya Erkan Akansu² ${ }^{2}$ Fuat Karakaya ${ }^{3}$, Cihan Yesildag ${ }^{2}$ and Hürrem Akbıyık ${ }^{4}$ \\ ${ }^{1}$ Karadeniz Technical University, Mechanical Engineering Department, 61080 Trabzon, Turkey \\ ${ }^{2}$ Nigde University, Mechanical Engineering Department, 51200 Niğde, Turkey \\ ${ }^{3}$ Nigde University, Electrical and Electronics Engineering Department, 51200 Niğde, Turkey \\ ${ }^{4}$ Cukurova University, Mechanical Engineering Department, 01380 Adana, Turkey
}

\begin{abstract}
A promising novel actuator called Spark-Plug Plasma Synthetic Jet (SPSJ) has been developed in Atmospheric Plasma Research Laboratory at Niğde University. It generates electrothermally high synthetic jet velocity by using high voltage. SPSJ actuator can be utilized to be an active flow control device having some advantages such as no moving parts, low energy consumption and easy to integrate the system. This actuator consists of two main components: semi-surface spark plug (NGK BUHW) as an anode electrode and a cap having an orifice as a cathode electrode. The cap, having a jet exit orifice diameter of $2 \mathrm{~mm}$, has diameter of $4.4 \mathrm{~mm}$ and height of $4.65 \mathrm{~mm}$. This study presents the characteristics of SPSJ actuator by using the hot wire anemometer in order to approximately determine jet velocity in quiescent air. Peak velocity as high as $180 \mathrm{~m} / \mathrm{s}$ was obtained for $\mathrm{f}_{\mathrm{e}}=100$ and duty cycle $50 \%$. The flow visualization indicated that the actuator's jet velocity is enough to penetrate the developed boundary layer.
\end{abstract}

\section{Introduction}

In recent years, active flow control (AFC) has been greatly drawn attention due to some advantages such as no moving parts, low energy consumption and without external air supply. Researchers have developed various devices based on plasma such as dielectric barrier discharge (DBD) actuator [1], DBD plasma synthetic jet actuator [2] and plasma spark jet (PSJ) actuator [3-5]. Especially PSJ actuators have very high jet velocity in comparison with the other plasma based actuator like DBD actuator.

A PSJ actuator called as a Sparkjet was developed by Grossmann et al. [3] at Johns Hopkins University Applied Physics Laboratory. This actuator had two electrodes inside a small cavity. The periods of this actuator consists of three different steps. Respectively, these are referred to as energy deposition, gas discharge and recovery. Moreover, the PSJ actuator can be classified as a two electrode [3,5 and 6] and a threeelectrode PSJ actuator [4, 7]. Explanations of these steps will be comprehensively explained in the section 2. Narayanaswamy et al. [6] carried out the experimental study via PSJ actuator having different cavity volume and orifice diameter. They had measured temperature of actuator by using optical emission spectroscopy and also obtained jet exit velocity of about $250 \mathrm{~m} / \mathrm{s}$ with consuming discharge energies of about 35 $\mathrm{mJ}$ per generated jet. Zong et al. [7] implemented to experimental study using three-electrode PSJ actuator having a volume of $1178 \mathrm{~mm}^{3}$ and an orifice diameter of $3 \mathrm{~mm}$. They measured jet exit velocity of about 230 $\mathrm{m} / \mathrm{s}$ by using the Schlieren method. According to the above mentioned literature results, this actuator can be effectively used in both subsonic and supersonic flow applications without moving parts and external air supply. But it also has some disadvantages, such as high price components (macorTM, high voltage power supply, etc.), and quick oxidation of actuator's electrodes.

This study has two purposes. The first is to explain how to develop a promising novel plasma synthetic jet based on spark-plug so as to use in flow control applications such as military and civilian aircraft. The second is to characterize the developed novel SPSJ actuator by using hot-wire anemometer in the quiescent air. Smoke-wire flow visualization experiments were also carried out to present how the developed SPSJ actuator can be affected the boundary layer developing over the flat plate.

\section{Experimental setup}

\subsection{Designed SPSJ Actuator}

A promising novel actuator called Spark-Plug Plasma Synthetic Jet (SPSJ) Actuator has been developed in Atmospheric Plasma Research Laboratory (APRL) at Niğde University. Developed SPSJ is inspired by

\footnotetext{
${ }^{\mathrm{a}}$ Corresponding author: mehmetseyhan@ktu.edu.tr
} 
internal combustion gasoline engine. The engine cylinder with spark plug has very big volume while our developed SPSJ has very small volume as well as an orifice. As shown in figure 1, SPSJ actuator which can be generated high synthetic jet velocity consists of two main components: semi-surface spark plug (NGK BUHW) as an anode electrode and a cap having an orifice that is made of aluminum as a cathode electrode. This cap, having orifice diameter of $2 \mathrm{~mm}$, has diameter of $4.4 \mathrm{~mm}$ and height of $4.65 \mathrm{~mm}$. The cavity volume is almost $70 \mathrm{~mm}^{3}$.

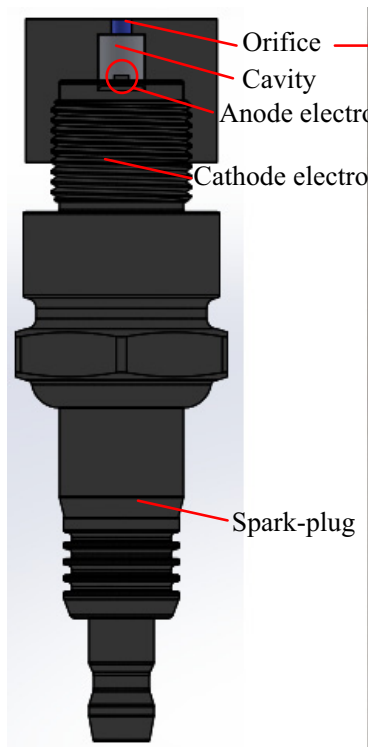

(a)

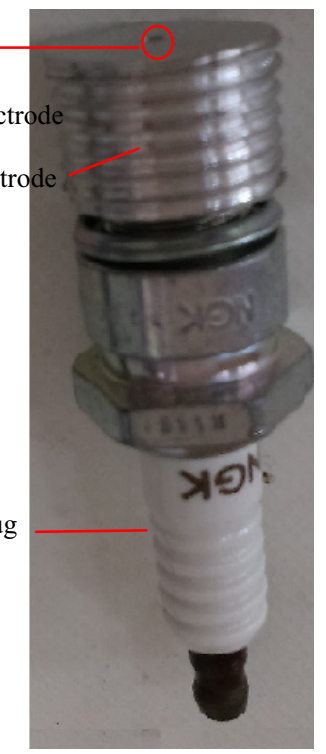

(b)
Figure 1. (a) Schematic view of developed SPSJ actuator, (b) Photo of developed SPSJ actuator.

The process of this actuator consists of three different steps which is same as the PSJ actuator [3]. As illustrated in figure 2, these are referred to as energy deposition, gas discharge and recovery respectively. The cap creates the cavity volume so as to heat rapidly the air in the cavity and then bring about suddenly augmentation pressure of the air, when applied pulse DC high voltage between these electrodes. End of this period, pressure of the air is very high compared to the ambient air and this pressurized air is expelled at high velocity through the orifice. Afterwards, the air pressure, which is dropped under the ambient pressure in the cavity, generates vacuum inside the cavity. Therefore, the ambient air is drawn into the cavity and the SPSJ actuator is ready for another cycle.

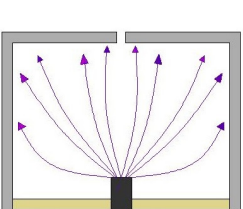

Energy Deposition

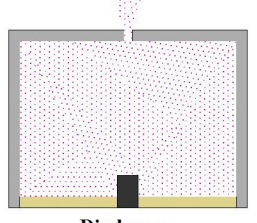

Discharge

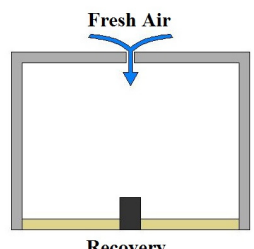

Recovery
Figure 2. Process of Spark-Plug plasma synthetic jet.

\subsection{Power Supply}

Belinger et al. [8] mentioned about two type power supply that can work the actuator. One is a high voltage power supply to commute high voltage directly during stage of discharge. The other is a low voltage power supply associated with a high voltage transformer and a transistor. According to this, we design a low voltage power supply associated with the high voltage transformer in this study. Designed power supply consists of a DC power supply, a high-voltage transformer and a MOSFET switch. DC power supply $\left(\mathrm{PACIFIC}^{\mathrm{TM}}\right.$ ), which has output $30 \mathrm{~V}$ and $5 \mathrm{~A}$, is connected to developed low cost DC high voltage transformer, which is worked between $2-6 \mathrm{~V}$ input, having maximum $400 \mathrm{kV}$ output. The MOSFET switch is also inserted in the ground line between DC power supply and the high voltage transformer. The MOSFET switch is controlled by an arbitrary wave generator (AATech-AWG-1010) which can be adjusted with the actuator excitation to get desired frequency. As shown in figure 3 , input current was measured by Fluke $80 \mathrm{i}-$ 110a AC/DC current probe which is monitored with the help of Tektronix model TDS2012B oscilloscope. Another oscilloscope was also used for signal visualization generated by function generator. Input mean voltage $\left(\mathrm{V}_{\mathrm{m}}\right)$ and the current $\left(\mathrm{I}_{\mathrm{pp}}\right)$ was measured as $\mathrm{V}_{\mathrm{m}}=2 \mathrm{~V}$ and $\mathrm{I}_{\mathrm{pp}}=2.48$ A respectively.

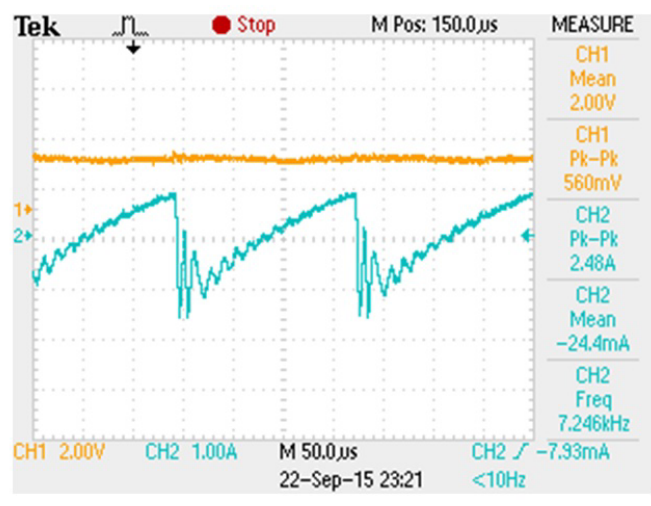

Figure 3. Captured image from oscilloscope in order to present input mean voltage and peak to peak current

\subsection{Measurement Devices}

The experiments were conducted to determine the characteristic of the developed novel SPSJ actuator by using hot-wire anemometer in the quiescent air. Hotwire measurement, which is measured the instantaneous air velocity, was carried out by using the Dantec 55P11 single wire probe. This probe operates together with Dantec Multichannel Constant Temperature Anemometer (CTA). The hot-wire probe was calibrated in a nozzle calibrator against a micromanometer. For each measurement, 32000 data was collected from the hot-wire at a sample frequency of $4 \mathrm{kHz}$ with the help of NI PCIe-6323 DAQ card. The probe was positioned at jet axis. It was placed on computer controlled two axis traverse mechanism so as to drive sensitively to the desired location on $\mathrm{x}$ and $\mathrm{y}$ axis. Secondly, Smoke-wire 
flow visualization experiment was implemented to present the effects of the SPSJ actuator on flow over the flat plate with the free stream velocity of $1.5 \mathrm{~m} / \mathrm{s}$. The SPSJ actuator was vertically placed on the flat plate in the open-type wind tunnel having a square cross-section $57 \mathrm{~cm} \times 57 \mathrm{~cm}$ in the Aerodynamics Research Laboratory of the Mechanical Engineering department at Niğde University. Both the leading edge and the trailing edge of the flat plate are beveled.

\section{Results}

\subsection{Velocity measurements by using hot-wire anemometer}

In order to present characteristic of the developed SPSJ actuators, instantaneous velocity measurement is being carried out with the help of the hot wire anemometer in quiescent air at the probe location above $6 \mathrm{~mm}$ from the top surface of the cap. As illustrated in figure 4, the instantaneous velocity distribution as a function of time was presented for different duty cycle changing between $10 \%$ and $90 \%$ in driving frequency of $0.5 \mathrm{~Hz}$. Peak instantaneous velocity is as high as $175 \mathrm{~m} / \mathrm{s}$ which was obtained at duty cycle of $90 \%$. On the other hand, in the velocity time history, some of the jet velocities weren't exactly acquired rightly because of insufficient sampling frequency of the hot-wire anemometer. Therefore, the peak jet velocities obtained randomly due to very small jet formation time according to efficient sampling period. As clearly shown in figure 4, the used low-cost high voltage power supply has instable characteristic during the elapsed time. It sometimes provides enough energy to SPSJ actuator but it doesn't. In this case, instantaneous velocities acutely change. As duty cycle decrease from $90 \%$ to $10 \%$, peak velocities significantly diminish. At the low duty cycle, the discharge time is too short in order to obtain enough energy for producing plasma in comparison with other duty cycle rate; therefore the produced plasma by giving energy to the cavity volume generates the low jet velocity.

Figure 5 shows effect of the variation of duty cycle on the instantaneous velocity distribution at $\mathrm{f}_{\mathrm{e}}=1 \mathrm{~Hz}$. Peak jet velocity is as high as $145 \mathrm{~m} / \mathrm{s}$ which was obtained at the duty cycle of $90 \%$ and $75 \%$. At $\mathrm{f}_{\mathrm{e}}=1 \mathrm{~Hz}$, there is no significant effect of different duty cycles over peak jet velocity for the range of duty cycle from $25 \%$ to $90 \%$. For duty cycle $10 \%$, the first pulse jet was obtained as high as $90 \mathrm{~m} / \mathrm{s}$ but the actuator doesn't produce strong enough jet at the other periods. Aforementioned problems are valid for this case such as instability of power supply and sampling sensitivity of the measurement.

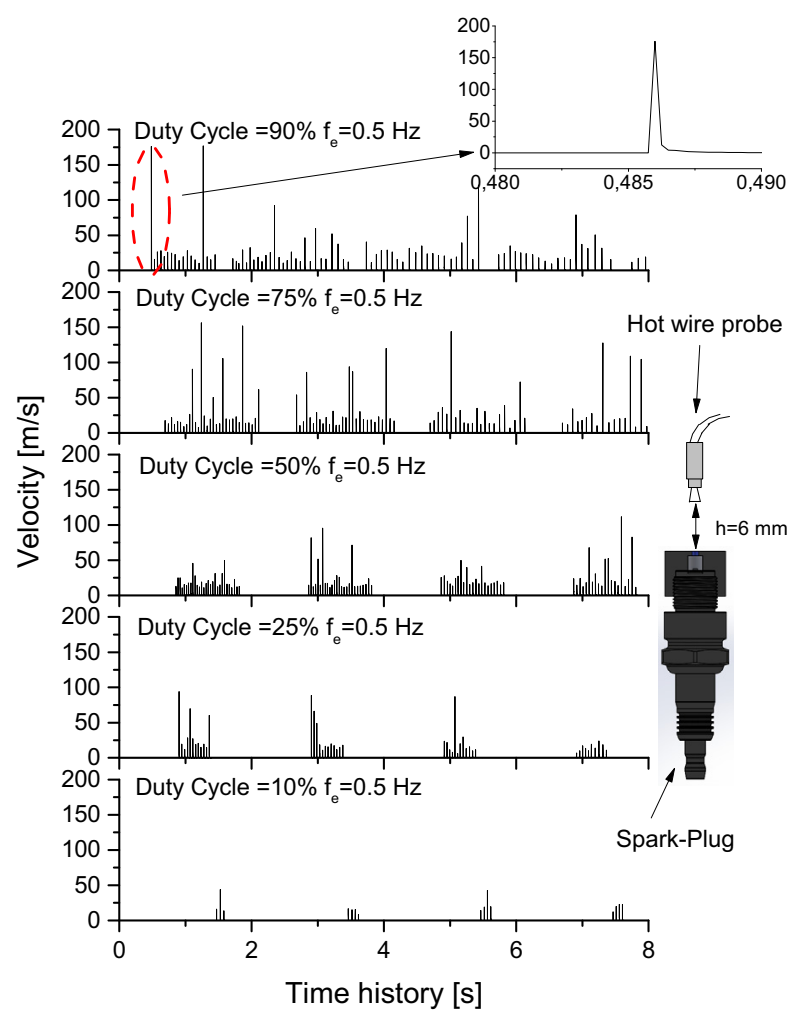

Figure 4. Effect of the variation of duty cycle on the instantaneous velocity distribution at $\mathrm{f}_{\mathrm{e}}=0.5 \mathrm{~Hz}$.

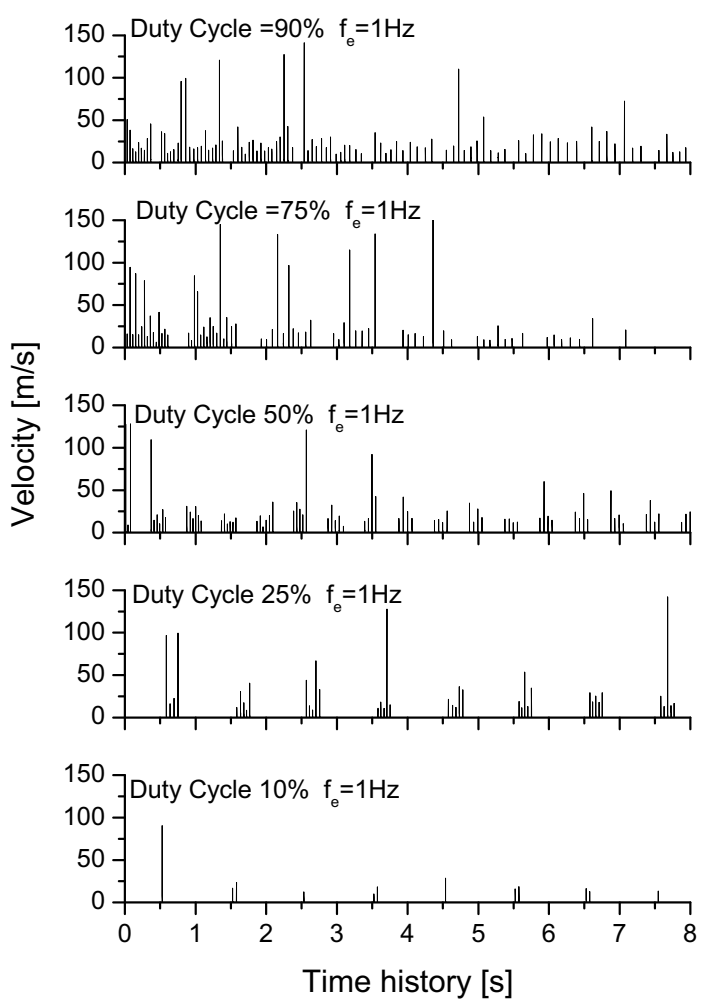

Figure 5. Effect of the variation of duty cycle on the instantaneous velocity distribution at $\mathrm{f}_{\mathrm{e}}=1 \mathrm{~Hz}$.

As illustrated in figure 6 , the instantaneous velocity distribution as a function of time was presented for different excitation frequency, changing from $\mathrm{f}_{\mathrm{e}}=0.2 \mathrm{~Hz}$ to $\mathrm{f}_{\mathrm{e}}=100 \mathrm{~Hz}$, at duty cycle of $50 \%$. As clearly seen from figure 6 , there is no significant change in peak value of the instantaneous velocity but the repetition of 
the jet decreases by the increasing of the excitation frequency due to characteristic of power supply at the high excitation frequency. Peak instantaneous velocity is obtained $180 \mathrm{~m} / \mathrm{s}$ which are highest velocity in comparison with the other excitation frequencies for $f_{e}$ at $100 \mathrm{~Hz}$.
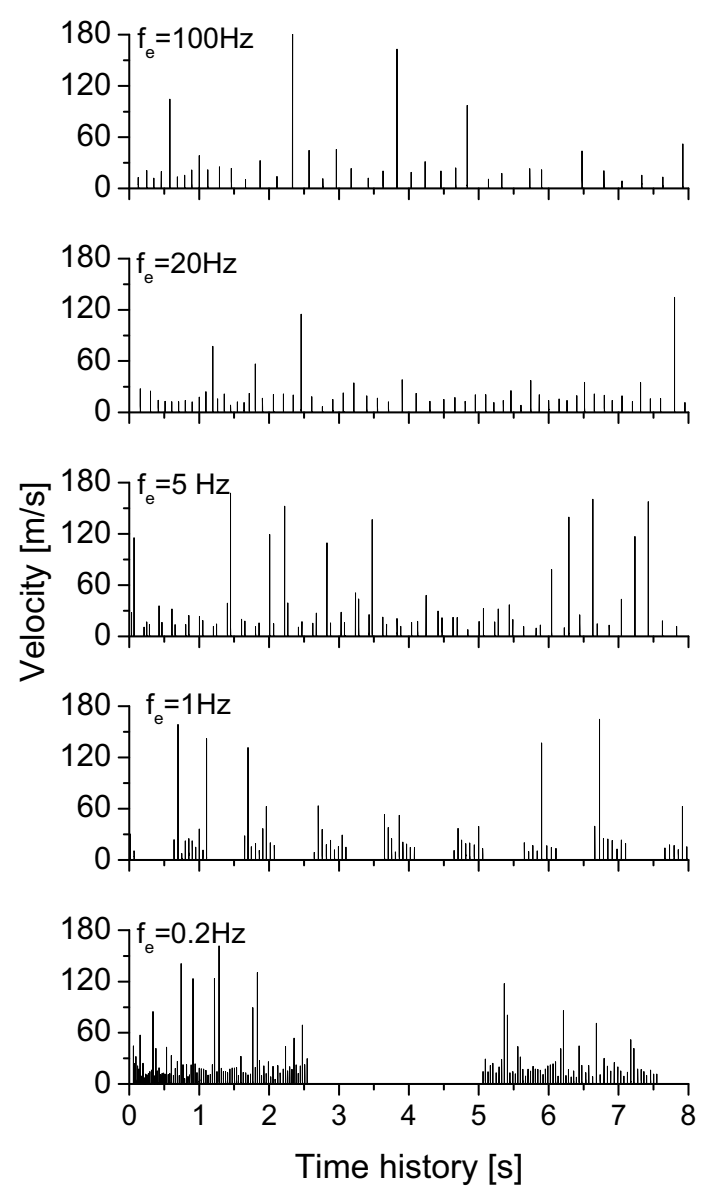

Figure 6. Effect of the variation of excitation frequency on the instantaneous velocity distribution at duty cycle $50 \%$.

\subsection{Flow visualization}

As shown in figure 7, the smoke-wire flow visualization experiments were carried out to present how the developed SPSJ actuator, which generates high jet velocity, can affect the boundary layer developing over the flat plate from leading edge to trailing edge. The first captured photo shows velocity field in the actuator off situation. The other captured photos show the perturbation effect of the SPSJ actuator's jet on the flow. These photos present the evolution of jet at different time inside the developed boundary layer. It should be noted that this visualization also shows the ability of the actuator in order to use the active flow control applications. Periodically generated jets are shown as a short line during the exposure time of the camera in the frame. Produced jets having different velocity submerged into the boundary layer and some of them, which are high velocity in nature, penetrate the shear layers.
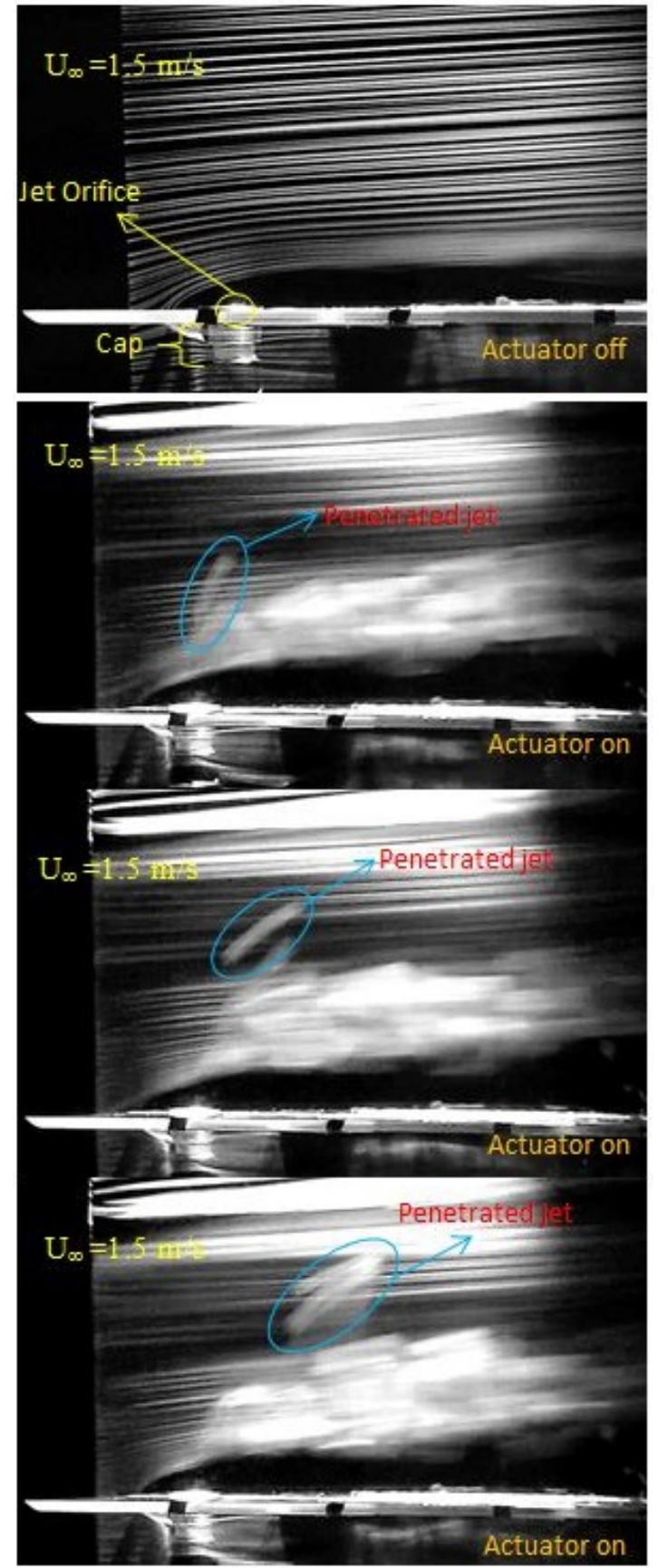

Figure 7. Effects of evolution of jet inside boundary layer developing over the flat plate.

\section{Conclusions}

A promising novel SPSJ actuator was developed so as to use in AFC applications. Characteristics of the developed SPSJ actuator was also investigated by using hot-wire anemometer in the quiescent air. Peak velocity was obtained as high as $180 \mathrm{~m} / \mathrm{s}$ for $\mathrm{f}_{\mathrm{e}}=100$ and duty cycle $50 \%$. Smoke-wire flow visualization experiment was implemented to present the effects of the SPSJ actuator on flow around the flat plate. The flow visualization indicates that the actuator's jet velocity is enough to penetrate the developed boundary layer. Evolution of the jet inside boundary layer is clearly presented. These results revealed that the SPSJ actuator is a promising and satisfying for the AFC application 
but we haven't enough qualified equipment such as high speed Schlieren system in order to make a precise measurement of this developed actuator.

\section{Acknowledgements}

The authors would like to acknowledge the financial support of this work by the Scientific and Technological Research Council of Turkey (TUBITAK) under the Contract Number of 213M179.

\section{Nomenclature}

$\mathrm{V}$ applied plasma voltage

$f_{e} \quad$ excitation frequency of the actuator

$\mathrm{U}_{\infty} \quad$ freestream velocity

$\mathrm{h}$ distance between the probe and the cap

$\mathrm{AC}$ alternating current

DC direct current

\section{References}

1. E. Moreau, J.Phys. D: Appl. Phys., 40, 605-636 (2007)

2. A. Santhanakrishnan, J.D. Jacob, $44^{\text {th }}$ AIAA Aerospace Sciences Meeting and Exhibit, pp.317, (2006)

3. K.R. Grossman, B.Z. Cybyk, M.VanWie, AIAA, 57, (2003)

4. S.J. Haack, T. Taylor, J. Emhoff, B. Cybyk, $5^{\text {th }}$ Flow Control Conferance, 28, (2010)

5. B. Caruana, P. Barricau, P. Hardy, J.P. Cambronne, A. Belinger, AIAA, 1307, (2009)

6. V. Narayanaswamy, L.L. Raja, N.T. Clemens, AIAA J. 48, 297-305 (2010)

7. H.H. Zong, W. Cui, Y. Wu, Z.B. Zhang, H. Liang, M. Jia, Y.H. Li, Sensor Actuat. A-Phys. 222, 114$121(2015)$

8. A. Belinger, P. Hardy, P. Barricau, J.P. Cambronne, D. Caruana, J.Phys. D: Appl. Phys., 44, 365201, (2011) 